\title{
Vitamin D and all-cause mortality in older adults $>50$ years - data from The Irish Longitudinal Study of Ageing
}

\author{
Triona McNicholas ${ }^{1}$, Mark Ward $^{1}$, Anne Molloy $^{1}$, Martin Healy $^{2}$ and Eamon Laird ${ }^{1}$ \\ ${ }^{1}$ Trinity College Dublin, Dublin, Ireland and \\ ${ }^{2}$ St James's Hospital, Dublin, Ireland
}

\section{Abstract}

\section{Background}

Low 25-hydroxyvitamin D $(25(\mathrm{OH}) \mathrm{D})$ has been linked with adverse health outcomes, including cancer, cardiovascular disease and mortality. The Irish Longitudinal Study on Ageing (TILDA) has previously shown that $13.1 \%$ of the Irish population over 50 are deficient in $25(\mathrm{OH}) \mathrm{D}$, after adjusting for seasonality. The aim of this study is to assess whether low $25(\mathrm{OH}) \mathrm{D}$ concentrations are associated with all-cause mortality in the over 50s in Ireland.

\section{Methods}

Data from Wave 1 (2009-2011) of TILDA, a prospective population representative study of community dwelling adults aged over 50, were used. Blood was obtained during the health assessment, and analysis of $25(\mathrm{OH}) \mathrm{D}$ was performed. Mortality was confirmed through official death records, and all participant deaths between baseline and March 2017 were included. Logistic regression assessed whether baseline levels of $25(\mathrm{OH}) \mathrm{D}$, both continuous and categorised into deficient $(25(\mathrm{OH}) \mathrm{D}<30 \mathrm{nmol} / \mathrm{l})$, insufficient $(30<=25$ $(\mathrm{OH}) \mathrm{D}<50 \mathrm{nmol} / \mathrm{l})$ or sufficient $(25(\mathrm{OH}) \mathrm{D}>=50 \mathrm{nmol} / \mathrm{l})$, are associated with mortality.

Results

Of the 8,175 over 50 s recruited, $25(\mathrm{OH}) \mathrm{D}$ data was available for 5,388 participants. Of these, 366 individuals had died prior to March 2017. Higher concentrations of $25(\mathrm{OH}) \mathrm{D}$ were associated with lower odds of mortality (OR $0.70 ; 95 \%$ CI 0.60 , 0.81 , p-value), controlling for confounders. On categorising $25(\mathrm{OH}) \mathrm{D}$, those with insufficient $25(\mathrm{OH}) \mathrm{D}$ concentrations had higher odds of mortality than those with sufficient levels (OR 2.04; 95\% CI 1.48, 2.8; p-value <0.001). Stratifying between men and women, there was no gender difference in this association.

\section{Conclusion}

Insufficient baseline $25(\mathrm{OH}) \mathrm{D}$ concentrations are associated with an increased odds of all-cause mortality in community dwelling adults over 50 in Ireland. Further research evaluating whether treatment of vitamin D deficiency improves mortality is warranted.

\section{Conflict of Interest}

There is no conflict of interest 